\title{
MODELO DE CUIDAR EM ENFERMAGEM JUNTO ÀS MULHERES-AVÓS E SUA FAMÍLIA NO COTIDIANO DO PROCESSO DE AMAMENTAÇÃO ${ }^{1}$ NURSING CARE MODEL TOGETHER WITH WOMEN-GRANDMOTHERS AND THEIR FAMILIES IN THE DAILY PROCESS OF BREAST-FEEDING MODELO DE CUIDAR EN ENFERMERÍA JUNTO A LAS MUJERES-ABUELAS Y SU FAMÍLIA EN EL COTIDIANO DEL PROCESO DE AMAMANTACIÓN
}

\author{
Marizete Argolo Teixeira², Rosane Gonçalves Nitschke ${ }^{3}$
}

\begin{abstract}
${ }^{1}$ Este trabalho é parte da dissertação de mestrado apresentada ao Programa de Pós Graduação em Enfermagem (PEN) da Universidade Federal de Santa Catarina (UFSC), em dezembro de 2005.

${ }^{2}$ Mestre em Enfermagem. Doutoranda do Programa de Pós-Graduação em Enfermagem da Escola de Enfermagem da Universidade Federal da Bahia (UFBA). Professora Assistente do Departamento de Saúde da Universidade Estadual do Sudoeste da Bahia (UESB). Bolsista da Coordenação de Aperfeiçoamento de Pessoal de Nível Superior. Bahia, Brasil.

${ }^{3}$ Doutora em Filosofia de Enfermagem. Professora Adjunto do Departamento de Enfermagem da UFSC. Orientadora da dissertação. Santa Catarina, Brasil.
\end{abstract}

PALAVRAS-CHAVES: Aleitamento materno. Enfermagem. Relações familiares.
RESUMO: Este estudo tem como objetivo refletir sobre a implementação do modelo de cuidar em enfermagem junto a três mulheres-avós e sua família em processo de amamentação para a promoção, proteção e apoio ao aleitamento materno no cotidiano familiar. O modelo de cuidar em enfermagem foi elaborado à luz da Teoria do Interacionismo Simbólico, integrando os momentos: Conhecendo o Cotidiano e as Interações; Definindo a Situação do Cotidiano e do Cuidado; Propondo e Realizando o Cuidado; Repensando sobre o Cuidado e o Cotidiano, sendo desenvolvido em encontros individuais e grupais numa unidade de alojamento conjunto e domicílios em Florianópolis - SC, de novembro a dezembro de 2004. A sistematização do cuidado às mulheres-avós, possibilitou levá-las a práticas cuidativas hospitalar e domiciliar às suas filhas, noras e netos em processo de amamentação. Concluiu-se que o modelo de cuidar é viável, ao sistematizar o cuidado às mulheres-avós e aos seus familiares em processo de amamentação.
KEYWORDS: Breast feeding. Nursing. Family relations.
ABSTRACT: The objective of this study is to reflect upon the implementation of a nursing care model together with three women-grandmothers and their families in the breast-feeding process, in order to promote, protect, and support maternal breast-feeding in daily family life. The nursing care model was elaborated according to the Theory of Symbolic Interactionism, integrating the following instances: Defining the Daily Situation and the Care Situation; Proposing and Carrying Out Care; Rethinking Care and Daily Life. It was developed through individual and group meetings in a shared living environment and in homes in Florianópolis, SC, Brazil in November and December of 2004. The systematization of care for women-grandmothers made it possible for them to take hospital and domicile care practices to their daughters, daughters-in-law, and grandchildren in the breast-feeding process. We conclude that the care model is viable, upon systematizing care for women-grandmothers and their family members involved in the breast-feeding process.
PALABRAS CLAVE: Lactancia materna. Enfermería. Relaciones familiares.
RESUMEN: Este estudio tiene como objetivo reflexionar sobre la implementación del modelo de cuidar en enfermería junto a tres mujeres-abuelas y su familia en el proceso de amamantación para la promoción, protección y apoyo a la lactancia materna en el cotidiano familiar. El modelo de cuidar en enfermería fue elaborado según la Teoría de la Interacción Simbólica, integrando los siguientes momentos: Conociendo el Cotidiano y las Interacciones; Definiendo la Situación del Cotidiano y del Cuidado; Proponiendo y Realizando el Cuidado; Reflexionando sobre el Cuidado y el Cotidiano. Ese modelo fue desarrollado en encuentros individuales y grupales en una unidad de alojamiento conjunto y en domicilios en la ciudad de Florianópolis/SC, en los meses de noviembre a diciembre de 2004. La sistematización del cuidado a las mujeres-abuelas, posibilitó llevar a sus hijas, nueras y nietos en proceso de lactancia, a las prácticas del cuidado hospitalario y domiciliario. Se concluyó que el modelo de cuidar es viable, al sistematizar el cuidado a las mujeres-abuelas y a sus familiares en proceso de lactancia.
Marizete Argolo Teixeira

Endereço: Al. Carrara, 316 Ed. Cidade de Málaga, Ap. 203

41.830-590 - Pituba, Salvador, BA, Brasil.

E-mail: marizete@uesb.br
Relato de experiência Recebido em: 16 de julho de 2007 Aprovação final: 10 de janeiro de 2008 


\section{INTRODUÇÃO}

Os aspectos sócio-econômicos e culturais têm influenciado de maneira significativa a prática do aleitamento materno, que embora seja um ato natural, não é instintivo, uma vez que as puérperas precisam ser apoiadas e ensinadas para realizarem esta prática de forma prazerosa evitando assim o desmame precoce.

Várias razões são apontadas para o desmame precoce, as quais nem sempre são assumidas pelas mães, que atribuem o desmame a problemas como: leite fraco, em pouca quantidade, mamilo invertido, mamilos doloridos, choro intenso do bebê, falta de sono, recusa o peito e a falta de apoio de profissionais de saúde, parentes, vizinhos e amigos. ${ }^{1}$

Ainda nos deparamos com outras situações que refletem a falta de informações e segurança da mãe sobre as vantagens do leite materno para a mulher e para o bebê, para a família, para a sociedade e para o planeta como: o uso da chupeta, de bicos, de água e chás no intervalo das mamadas; o despreparo dos profissionais de saúde para resolução dos problemas mais comuns da amamentação; a propaganda dos leites industrializados; a fraca atuação dos serviços de saúde, no apoio à mãe nutriz e à família para que consigam resolver os principais problemas decorrentes da amamentação.

A defesa da lactação natural, na metade do século XX, não acontecia de forma coletiva, e sim individual, principalmente depois da industrialização, onde a divulgação do leite artificial acontecia de forma rotineira. Falava-se muito pouco do aleitamento materno, o que fez as mulheres acreditarem mais no leite artificial do que no aleitamento natural. ${ }^{2}$

Na década de 70, começa a mudar a percepção sobre a prática da amamentação devido ao elevado índice de morbimortalidade infantil. Nesta época, o Brasil apresentava indicadores de saúde alarmantes: a mortalidade infantil era de 88 por mil nascidos vivos, 124 por mil na região Nordeste; a desnutrição crônica vitimava $48 \%$ da população brasileira; o desmame precoce no primeiro mês de vida atingia $54 \%$ dos lactentes na cidade de São Paulo e $80 \%$ em Recife; $50 \%$ dos pediatras prescreviam mamadeiras e $90 \%$ aconselhavam o uso de água nos intervalos das mamadas. ${ }^{3}$

Atualmente, a política de saúde da criança no Brasil tem priorizado, dentre outras, ações de promoção, proteção e apoio ao aleitamento materno, como estratégia fundamental para a redução da mortalidade infantil no país e para a melhoria da qualidade de saúde das crianças brasileiras. ${ }^{4}$ Nesta luta pela lactação natural é imprescindível a participação de todos, principalmente dos familiares, dentre os quais, podemos citar as mulheres-avós.

A opinião da mulher-avó é válida. Ela é herdeira de um processo cumulativo de conhecimentos advindos de sua vivência e experiências adquiridas ao longo dos anos, tornando-a valorizada e respeitada. Porém nas questões referentes ao aleitamento materno, as mulheres-avós, muitas vezes, interferem incentivando o uso de líquidos e/ ou outros alimentos. Acreditamos que estas atitudes das avós estejam relacionadas com o contexto histórico vivido pelas mesmas, quando a prática da amamentação ainda não era valorizada.

Diante disto, entendeo que é preciso repensar e encontrar junto às mulheres-avós, maneiras de re-significar a amamentação com intuito de promovê-la, protegê-la e apoiá-la quando exercerem o cuidado intrafamiliar à mulher nutriz $\mathrm{e}$ seus familiares no cotidiano do processo de amamentação, o que poderá contribuir para reduzir o desmame precoce e, assim, contribuir para a melhoria da qualidade de vida das crianças e futuramente de adultos mais saudáveis, visto que o aleitamento materno é um dos cuidados primordiais para o viver.

Este artigo, realizado a partir de uma dissertação de mestrado, ${ }^{5}$ tem como objetivo refletir sobre a implementação do Modelo de Cuidar em Enfermagem (MCE) junto a mulheres-avós e sua família em processo de amamentação para a promoção, proteção e apoio ao aleitamento materno no cotidiano familiar.

O MCE é uma atividade intelectual deliberada, pela qual a prática de enfermagem é implementada de forma sistemática e ordenada, sendo uma tentativa de melhorar a assistência. É uma forma de cuidado baseada em crenças, valores e significados no processo de viver dos envolvidos no seu cotidiano. ${ }^{6-7}$ Assim, para sustentá-lo, utilizei os fundamentos do Interacionismo Simbólico.

A temática em questão foi escolhida em virtude das autoras terem percebido a influência das mulheres-avós na prática do aleitamento materno ao exercerem cuidado intrafamiliar às suas filhas, noras e netos em processo de amamentação, sendo estas influências permeadas por crenças, mitos e tabus levando, muitas vezes, as nutrizes a desmamarem precocemente seus filhos. 


\section{REFERENCIAL TEÓRICO-METODOLÓ- GICO}

O Interacionismo Simbólico é uma perspectiva teórica da ciência, formada por um conjunto de idéias sobre a natureza das pessoas e a sociedade, com o foco na interação humana ao propor uma base para o entendimento do significado na interação entre os seres humanos. ${ }^{8}$

São três as premissas básicas do Interacionismo Simbólico: 1) o ser humano age com relação às coisas na base dos sentidos que elas têm para ele. Estas coisas incluem todos os objetos físicos, outros seres humanos, categorias de seres humanos, instituições, idéias valorizadas, atividades dos outros e outras situações que o indivíduo encontra na sua vida cotidiana; 2) o sentido destas coisas é derivado, ou surge, da interação social que alguém estabelece com seus companheiros e 3) estes sentidos são modificados através de um processo interpretativo usado pela pessoa ao tratar as coisas que ela encontra. ${ }^{9}$

Baseado nestas premissas, busquei conhecer o significado que o aleitamento materno tinha para as mulheres-avós, para em seguida compreender como elas interagiam com suas filhas, noras e netos quando, em seu quotidiano, exerciam o cuidado intrafamiliar às mesmas. Isto permitiu modificar alguns significados a partir das interações e de resignificações, utilizando um processo interpretativo usado pelas mulheres-avós ao tratar das questões relacionadas à prática da amamentação.

O MCE emergiu a partir de alguns trabalhos, ${ }^{6,10-13}$ constituindo-se pelos seguintes momentos - Conhecendo o cotidiano e as interações; Definindo a situação do cotidiano e do cuidado; Propondo e realizando o cuidado e Repensando sobre o cuidado e o cotidiano.

Conhecendo o cotidiano e as interações, foi o momento da interação inicial da enfermeira com as mulheres-avós, com os familiares e com os profissionais da instituição, momento em que os conheci e deixei-me conhecer. Foram esclarecidos os objetivos, a justificativa e os princípios bioéticos da pesquisa com seres humanos. Busquei também conhecer a história da família e a maneira de viver pela qual eles estavam envolvidos no processo de amamentação.

Ao efetivar o momento definindo a situação do cotidiano e do cuidado, busquei junto às mulheres-avós e demais familiares definir a situação que estavam vivenciando em seu cotidiano, em especial o significado da amamentação para as mulheres-avós, como as mesmas experienciaram e vivenciaram a prática do aleitamento materno e como elas iriam cuidar da filha, nora, netos e netas em processo de amamentação. Identifiquei as necessidades de cuidado das mulheres-avós para cuidar da mulher nutriz. Assim, nesta fase, foi possível reconhecer os riscos para o desmame precoce, identificando quais fatores poderiam influenciar e dificultar a amamentação.

No momento Propondo e realizando o cuidado, foram propostos e implementados os cuidados identificados a partir do Conhecimento do cotidiano e das interações e da Definição da situação do cotidiano e do cuidado, envolvendo a identificação das necessidades de cuidado das mulheres-avós às puérperas, neto, netas, genro e filhos, para, em seguida, implementá-los. Os cuidados, em sua maioria, foram discutidos antes de serem implementados. As ações integraram-se à prescrição da enfermeira da instituição, enquanto a puérpera estava internada. No domicílio, os cuidados foram implementados pelas mulheres-avós e pela enfermeira. Ao implementar os cuidados, a enfermeira também cuidava das mulheres-avós e das puérperas. As mulheres-avós cuidavam da puérpera com base nos cuidados que recebia da enfermeira, caracterizando-se em um processo dinâmico e interativo.

Ao Repensar sobre o cuidado e o cotidiano, realizei uma avaliação sobre os cuidados que foram propostos e implementados e como estes haviam auxiliado na resolução dos problemas surgidos refletindo sobre as interações estabelecidas. Esta fase foi desenvolvida com as mulheresavós e puérperas no intuito de repensar e propor possibilidades de interação acerca do cotidiano vivenciado pelas mesmas. Este momento reforçava e articulava as demais etapas entre si, permeando todo o MCE, na medida em que servia para avaliar o cuidado proposto, no sentido de dar continuidade ou realizar modificações, caso houvesse necessidade. Desta forma, esta etapa subsidiou e retroalimentou todo o MCE.

A implementação do MCE ocorreu de novembro a dezembro de 2004 em uma unidade de alojamento conjunto de um hospital público na grande Florianópolis e nos domicílios das famílias, utilizando encontros individual e em grupo e como estratégia de coleta de dados a entrevista semi-estruturada e a observação participante, tendo como informantes 3 mulheres-avós que estiveram acompanhando suas filhas, noras, neto e netas em processo de amamentação. Atribui-se às informan- 
tes nomes de pedras preciosas; Brilhante (65 anos, 11 filhos, cuidou da nora e da neta); Pérola (56 anos, 4 filhos, cuidou da filha e do neto) e Esmeralda (63 anos, 5 filhos, cuidou da nora e da neta).

O registro do MCE foi realizado em Diário de Campo, utilizando-se como nomenclatura de identificação as Notas de Entrevistas (NE); Notas de Observação (NO); Notas Teóricas (NT); Notas Metodológicas (NM); Notas de Cuidado (NC) e Notas do Diário (ND), conforme proposta de estudiosos. ${ }^{14}$

Em todos os momentos foram garantidos o anonimato e privacidade das informações, considerando os princípios éticos que envolvem a pesquisa com seres humanos, estabelecidos pela Resolução No 196/96 do Conselho Nacional de Saúde. ${ }^{15} \mathrm{O}$ projeto de pesquisa foi aprovado pelo Comitê de Ética em Pesquisa da Universidade Federal de Santa Catarina, sob o No 162/05.

\section{COMO SE DESENVOLVERAM AS ESTRA- TÉGIAS E O CUIDADO ÀS PRECIOSIDA- DES E SEUS FAMILIARES}

O primeiro encontro aconteceu na unidade de alojamento conjunto e foi marcado pelo início da interação entre a enfermeira, a mulher-avó, a puérpera, os recém-nascidos, os companheiros e demais familiares. Em seguida convidei a mulheravó para participar do primeiro Encontro Individual. Neste momento, discuti de modo mais aprofundado, os objetivos do estudo, a metodologia a ser desenvolvida, bem como as questões éticas da pesquisa. Apresentei o Termo de Consentimento Livre e Esclarecido, solicitando autorização para realização da pesquisa.

Desenvolvi o primeiro encontro com cada mulher-avó de forma individual porque não consegui reuni-las, uma vez que elas apareceram no estudo em momentos distintos. Este encontro teve como objetivo responder às seguintes questões norteadoras: $\mathrm{O}$ que é amamentação para você? Como foi sua experiência com a amamentação?

Esse encontro individual teve a seguinte seqüência: entrega da massa de modelar de diversas cores para que a mulher-avó expressasse o significado da amamentação, através de uma modelagem. O método criativo de modelagem foi utilizado com intuito de dinamizar o processo de cuidar e como uma forma criativa de cuidar da mulher-avó. Em seguida, elas descreveram a sua modelagem, expressando desta forma, o significado que a amamentação tinha para elas.
Relataram também como foi a sua experiência com a amamentação.

Conforme iam relatando seus significados e suas vivências, eu anotava alguns pontos que me chamavam a atenção para, em seguida, discutir com as mesmas, podendo re-significar alguns conceitos e cuidados. Foi uma forma de cuidar, confrontar o que elas haviam vivenciado com o encontrado na literatura, ao mesmo tempo em que utilizava uma outra forma de cuidado bastante sensível, o de ouvir.

Este foi um momento bastante rico, onde pude perceber o significado do aleitamento materno, crenças, tabus e valores, sendo que alguns deles poderiam ser prejudiciais no processo de cuidado da avó para com sua filha, nora e neto, quando visto pelo olhar profissional. Então, os cuidados desenvolvidos nesta etapa foram importantes para nortear o MCE, sendo um momento onde vários pontos foram identificados, reforçando a pertinência das fases Conhecendo o cotidiano e as interações, bem como Definindo a situação do cotidiano e do cuidado.

\section{MERGULHANDO NO COTIDIANO DO- MICILIAR DAS PEDRAS PRECIOSAS}

Foram realizadas três visitas domiciliares para cada mulher-avó e sua família. Nessas visitas domiciliares, pude conhecer como estava acontecendo a interação entre a mulher-avó, sua filha ou nora, seu neto ou neta e demais familiares, bem como compreender como as mesmas estavam exercendo o cuidado no domicilio e, assim, promovendo, incentivando e apoiando o aleitamento materno no cotidiano familiar.

No domicílio, o MCE foi mais uma vez implementado, servindo para continuar a reflexão, discussão e construção, junto às mulheres-avós, sobre as maneiras de cuidados. Nestes encontros, as mulheres-avós e as puérperas interagiram de forma mais atuante, na medida em que participavam das discussões, e, assim refletiam sobre a importância da participação da família neste processo que envolve o nascimento de um novo ser.

Estes foram momentos nos quais os cuidados com as puérperas foram discutidos, estabelecidos e modificados, quando necessários. As mulheres-avós também foram cuidadas, sendo estimuladas a manter cuidados pertinentes e a repensarem sobre outros considerados prejudiciais ao processo de amamentação, a partir do saber profissional, mas sempre buscando respeitar o 
saber familiar. Elas foram apoiadas, tornando-se possivelmente mais seguras quando cuidavam de sua filha, nora e neto ou neta.

Mais uma vez, o ouvir, o educar e o trocar experiências foram elementos significativos do cuidado. Percebi que os momentos mais enfatizados do MCE foram o Propondo e realizando o cuidado, bem como o Repensando sobre o cuidado e o cotidiano.

\section{O ENCONTRO DAS PEDRAS PRECIOSAS}

Este encontro foi realizado com as mulheresavós. Estiveram presentes Pérola e Brilhante, estando ausente Esmeralda por motivo de uma viagem inesperada. O objetivo desse encontro em grupo foi o de promover o encontro das pedras preciosas para que as mesmas relatassem como elas haviam cuidado de suas filhas, noras, netos e netas do nascimento até o primeiro mês de vida do recém-nascido. Serviu também para que as mulheres-avós interagissem entre si. O encontro caracterizou-se como uma oficina, uma vez que utilizamos dinâmicas criativas e sensíveis, construindo-desconstruindo-reconstruindo os significados da amamentação, porém com outra visão, a de serem cuidadoras de sua filha, nora e netos. Nessa oficina, foi trabalhada a seguinte questão norteadora: Como foi a experiência de cuidar da filha ou nora e neto ou neta em processo de amamentação?

A oficina constou dos seguintes momentos: relaxamento de acolhimento, atividade central e relaxamento de integração. ${ }^{10}$ No momento de relaxamento de acolhimento, pudemos identificar a etapa do Conhecendo o cotidiano e as interações. Preparei o ambiente recebendo as mulheres-avós com música, orientando-as a realizar exercícios respiratórios, de alongamentos e relaxamento simples. Este foi um momento, em que as apresentei uma a outra, deixando-as falarem um pouco de si.

Em seguida, procedi à atividade central, lançando a questão norteadora: como foi a sua experiência em ter cuidado de sua filha ou nora em processo de amamentação? Para responder a esta questão utilizei a dinâmica da "Linha do Tempo", momento em que se foi Definido a situação do cotidiano e do cuidado.

Ofereci material, explicando-lhes como seria a dinâmica, informando que as mesmas iriam traçar a "Linha do Tempo", ou seja, iriam recordar como foi a experiência de cuidar de sua filha ou nora e neto ou neta em processo de amamentação a cada semana. Mostrei-lhes também as placas que confeccionei para demonstrarem como foram estas semanas: a placa que se referia a facilidade era demonstrada utilizando uma linha contínua; para expressar poucas dificuldades, utilizavam uma linha quebrada ao meio; e com muitas dificuldades, uma linha tracejada. Resolvi fazer desta forma, porque uma das mulheres-avós era analfabeta, a fim de facilitar seu entendimento. Perguntei se queriam construir por partes, ou seja, completarem a linha, para depois expressarem o que haviam construído. Elas preferiram ir construindo por semana, relatando logo o que ocorrera naquela semana. Elas ouviram o relato uma da outra com bastante interesse, opinando e trocando experiências.

Esta dinâmica serviu para que as avós relatassem as facilidades e dificuldades vivenciadas durante este período de tempo e como lidaram com as situações. Houve histórias semelhantes e diferentes, o que possibilitou a troca de experiências entre elas, trazendo também solidariedade, uma vez que cada uma percebia que esse processo era permeado por tais dificuldades, facilidades, compromisso, responsabilidade e que a ajuda delas era extremamente importante neste processo do viver no cotidiano familiar.

Este foi um momento caracterizado como Propondo e realizado o cuidado, no qual mais uma vez, o dialogar, o refletir, o ouvir, o trocar experiências, orientar e o educar estiveram presentes na medida em que discutíamos sobre as dificuldades, facilidades e os cuidados que foram estabelecidos no MCE. Foi bem descontraído, havendo e uma troca entre as mulheres-avós e enfermeira. Os assuntos fluíam e eram discutidos de forma natural, proporcionando dessa forma, um crescimento para aquele grupo de pessoas.

Aproveitei o momento e dispus as modelagens que elas haviam feito no primeiro encontro individual. Elas ficaram felizes por eu ter guardado as expressões com todo carinho. Uma havia modelado "os peitos"; a outra, "uma criança" e a terceira mulher-avó, "uma gestante". Chamei-as até a mesa e fizemos uma reflexão sobre o que tinham modelado, destacando que é preciso olhar a puérpera como um todo, com corpo e mente; e, que o ato de amamentar, apesar de depender da mulher, é de responsabilidade de todos, especialmente dos familiares.

O passo seguinte foi realizar a avaliação da oficina, ou seja, Repensar sobre o cuidado e o cotidiano, no qual utilizei a dinâmica das carinhas. Mostrei-lhes três carinhas com as seguintes 
expressões: alegre, indiferente e triste. Pedi que elas escolhessem uma que expressasse como elas haviam chegado e como estavam saindo daquela oficina. Elas escolheram a carinha que representava alegria, justificando que os momentos que compartilhamos foram alegres e prazerosos. Após a avaliação saboreamos um lanche que eu havia preparado. Elas ficaram surpresas e agradecidas com mais este cuidado.

No relaxamento de integração, convidei as mulheres-avós a ficarem de pé, formamos um círculo e, ao som de uma música, refletimos sobre a importância do aleitamento materno e do nosso papel na promoção, proteção e apoio à prática da amamentação. Pedi que elas expressassem, com uma palavra, o que o estudo representou para elas. Brilhante disse que foram momentos de alegria, sentia-se muito a vontade comigo e que aprendera muitas coisas sobre amamentação. Pérola referiu que foram momentos de trocas de experiências, tendo sido muito bom ter alguém da área da saúde para discutir sobre os problemas que surgiram, o que a deixou mais segura para cuidar de sua filha e de seu neto. Relatou que ela havia trocado muitas experiências comigo referentes às questões do aleitamento materno. Falei que, para mim, foram momentos de muito aprendizado e troca.

Acredito que ter trabalhado com um grupo de mulheres-avós que promoviam, protegiam e apoiavam o aleitamento materno foi bastante desafiador no sentido de refletir sobre o papel delas na amamentação. Trocamos um afetuoso abraço coletivo e individual despedindo-nos em seguida.

\section{RELETINDO SOBRE O REFERENCIAL TEÓRICO-METODOLÓGICO QUE SUS- TENTOU O MODELO DE CUIDAR}

Quando busquei orientar minha prática com um olhar sustentado por uma teoria, fui capaz de produzir mudanças em determinadas situações. Assim, o Interacionismo Simbólico e seus conceitos atuaram como guia para direcionar as ações, auxiliando "a identificar o que era significativo observar, relacionar e planejar, além de oferecer subsídios para refletir e interpretar o que estava vivenciando". 6:180

O Interacionismo Simbólico, ao fundamentar esta pesquisa, apontou a necessidade de conhecer o significado que a amamentação tinha para as mulheres-avós, para saber como elas agiam com esta prática ao cuidarem de sua filha, noras, netos e netas em processo de amamentação. Significados estes, que surgiram da interação social cotidiana que elas estabeleceram com outras pessoas, como os filhos, a mãe, o esposo, os netos, os profissionais de saúde, dentre outros. Alguns significados precisaram ser construídos-desconstruídos-reconstruídos a partir das interações de negociação por meio do processo interpretativo usado pelas mulheres-avós ao tratar das questões relacionadas a essa prática.

O MCE foi uma atividade interativa intelectual, deliberada, flexível, em que a prática da enfermagem foi implementada de forma sistemática e ordenada, melhorando o cuidado prestado, na medida em que esse cuidado foi baseado na maneira de viver o dia-a-dia destes seres humanos.

O MCE permitiu perceber o quanto ele é dinâmico, pois suas etapas foram bem interrelacionadas, tamanha era a sua interligação e complementaridade. Em muitos momentos foi possível, conhecer o significado, propor um cuidado e implementá-lo em curto espaço de tempo, parecendo estar fazendo tudo simultaneamente. Ele foi capaz de nortear e sistematizar toda a prática da enfermeira. Sendo assim, ele pode ser utilizado no cotidiano da enfermeira, seja na área hospitalar, em uma unidade básica de saúde e no domicílio, de acordo com cada realidade vivenciada.

Vale ressaltar que o MCE procurou integrar conhecimentos e significados trazidos pelas mulheres-avós para, somente a partir destes, poder implementar cuidados que não fossem somente advindos do saber profissional, mas sobretudo, do compartilhamento de conhecimentos do saber popular de modo que se realizasse um cuidar com melhor qualidade.

As estratégias utilizadas para desenvolver o MCE deram vida ao mesmo, pois foram realizadas de forma dinâmica, tanto para a enfermeira como para as mulheres-avós, as puérperas, os companheiros e recém-nascidos. O encontro individual com alguns membros da família e com a mulher-avó possibilitou uma maior aproximação, acontecendo de forma diferente e peculiar com cada um deles. No encontro em grupo, a oficina proporcionou momentos prazerosos de crescimento individual e coletivo, à medida que favorecia a troca de experiências e a construção-desconstrução-reconstrução de significados, conhecimentos e cuidados.

A forma lúdica de trabalhar o MCE despertou nas mulheres-avós uma viagem no tempo à sua própria história, quando buscavam em sua memória como haviam vivenciado a prática do aleitamento materno em passado remoto (quando falavam de sua própria experiência) e em outro 
recente (quando falavam da experiência em estar cuidado de sua filha ou nora). Esses também foram momentos de descontração, de criatividade, de sensibilidade, revelando um verdadeiro mundo de símbolos e significados, ao mesmo tempo em que refletíamos sobre as nossas ações, os nossos conceitos, tabus, crenças e valores, permitindo, dessa forma que, encontrássemos uma maneira de cuidar que promovesse o aleitamento materno.

As dinâmicas utilizadas, além de terem possibilitando a interação dos participantes, reproduziram um despertar de emoções, sensibilidade e criatividade, fazendo surgir os significados acerca da amamentação de forma mais clara, uma vez que permitiram que as mulheres-avós trocassem experiências por meio da espontaneidade e da arte. Elas referiram sentirem-se valorizadas ao serem ouvidas, ao mostrarem sua obra de arte, ao descobrirem que tinham conhecimentos e que estes poderiam ser mostrados e trocados. Enfim, deram indicações de que esta foi uma forma de cuidar que se mostrou efetiva.

Quanto às visitas domiciliares, estas foram imprescindíveis para o $\mathrm{MCE}$, caracterizando-se como um verdadeiro mergulho no cotidiano das famílias. Significou estar perto de cada um no seu habitat, em seu nicho ecológico, local onde os seres humanos mostram muito de sua essência, sentindo-se mais seguros por estarem em um território delimitado por eles, configurando-se em um potencial para auxiliar os profissionais que desejam desenvolver um cuidado sintonizado na realidade das famílias.

As mulheres-avós mostravam-se mais abertas para encontrar formas de se cuidarem e cuidarem de seus membros. Ao demonstrarem sua satisfação em nos receber, levaram-nos a refletir sobre nossa postura profissional, acentuando que estes são momentos em que precisamos agir com cautela e bom senso, para não entrarmos em choque com suas crenças, seus valores e seu modo de vida. É necessário aprender a discutir, compartilhar e negociar os cuidados. A presença da enfermeira no domicílio foi relatada como uma possibilidade de reduzir a ansiedade, trocando experiências, contribuindo para as mulheres-avós cuidassem de sua filha, nora, netos e netas.

\section{ALGUMAS CONSIDERAÇÕES PARA FI- NALIZAR ESTE MOMENTO}

Considero o MCE, como um processo dinâmico, construído a partir da interação com cada mulher-avó, puérpera, recém-nascido e demais familiares, ressaltando que essa interação aconteceu de forma mais significativa com as mulheres-avós.

Trabalhar com a Teoria do Interacionismo Simbólico e seus conceitos foi fundamental. Essa teoria revelou a importância de se cuidar, enfocando os significados do aleitamento materno para as mulheres-avós, a fim de compreender suas interações com as noras, filha, neto, netas, possibilitando, assim, trabalhar com a realidade das mulheresavós que vivenciam a chegada de um novo ser em seu cotidiano, o qual precisa de cuidados.

A enfermeira foi importante neste processo de viver das famílias, na medida em que sua interação não foi estática, fechando-se apenas nas questões voltadas para o aleitamento materno, mas também ampliando-se para um cuidado que integra as diferentes dimensões do viver e do conviver das famílias. Cada mulher-avó desempenhou seu papel, dependendo do seu contexto histórico e de sua vivência e experiência com a prática do aleitamento materno, cuidando de forma prazerosa e com o conhecimento que possuía atrelado à sua experiência de vida, utilizando-se também dos novos conhecimentos que adquiriu com a enfermeira ao ser implementado o MCE.

Apesar de o estudo estar centrado na figura das mulheres-avós, as puérperas, os recém-nascidos, os companheiros, a irmã e os filhos de uma das puérperas também integraram este estudo, porém de forma tímida. Sem eles, jamais teríamos conseguido implementar o MCE. No entanto, acreditamos que, inserir os familiares no contexto, possibilitou uma interação maior entre seus membros, o que se traduz em um apoio à mulher nutriz e, conseqüentemente, numa promoção, proteção e apoio ao aleitamento materno.

A participação do companheiro esposo foi bem restrita, uma vez que, quase sempre estavam ausentes no momento das visitas tanto no hospital quanto nos domicílios. Entendo que as atividades do homem fora do lar o distancia do processo de amamentação. Também percebo que os papéis atribuídos aos homens os fazem ficar alheios a esse momento, o que nos convida a refletir sobre a necessidade de envolvê-los no processo de amamentação. Portanto, é preciso inserir mais efetivamente os companheiros das puérperas nos cuidados.

Mergulhar no mundo da família foi tarefa importante. Não podemos ficar restritos ao âmbito hospitalar, mas experimentar outros locais onde seja possível perceber a realidade cotidiana, sendo que os domicílios mostram-se um espaço indicado para realização desse mergulho, consi- 
derando-se devidamente os aspectos éticos que permeiam a visita domiciliar.

Por meio da interação na unidade de alojamento conjunto e nas visitas domiciliares, pude discutir, refletir, construir-desconstruir-reconstruir vários significados junto às mulheres-avós e sua família, o que possibilitou a resolução dos problemas que surgiram durante o processo de amamentação.

O MCE desenvolvido é viável por ser dinâmico, com suas fases, sempre se interligando e se completando, direcionando todo o cuidar às mulheres-avós e seus familiares. Vale salientar que o nosso cuidado precisa ser melhor direcionado na perspectiva da família e não apenas das mulheres-avós. Apesar do aleitamento materno estar sendo vivenciado pelas nutrizes e recémnascidos, ele pode ser experienciado por todos que desejam e podem contribuir para ajudar e apoiar a mulher que amamenta.

No caminho percorrido, também pude construir-desconstruir-reconstruir meus próprios significados, especialmente o de acreditar que as mulheres-avós somente interferiam no processo de amamentação de modo a promover o desmame precoce, noção concebida a partir do contexto social em que se convivia anteriormente. Ao me deparar com outra realidade, pude então perceber que as mulheres-avós interferem no processo de amamentação também de modo a estimular, promover, proteger e apoiar essa pratica.

Entretanto, percebi que elas precisam ser cuidadas não apenas para desenvolver de forma efetiva o cuidado, mas também porque são seres que demandam cuidados, passando também por crises em seu desenvolvimento, nas definições, modificações, reflexões e desempenho de papéis e a enfermeira pode ser uma profissional significativa para ajudá-las a realizar esse cuidado.

A experiência mostrou especialmente que as mulheres-avós são verdadeiras "pedras preciosas" uma vez que já vivenciaram e experienciaram a prática da amamentação, possuindo significados sobre aleitamento materno que, ao longo da história, foram sendo construídos-desconstruídosreconstruídos. Portanto, detentoras de muitos conhecimentos que podem contribuir para a implementação dos cuidados necessários à família em processo de amamentação.

A construção de um cotidiano de cuidado junto às mulheres-avós e seus familiares para a promoção, proteção e apoio ao aleitamento materno, mostra-nos a importância de cuidar das mesmas, ao envolvê-las não somente nos cuidados a suas filhas, noras e netos, mas, sobretudo, de abrir um espaço para que possam discutir as questões que permeiam a prática do aleitamento materno, mesmo sabendo que elas não mais amamentarão.

É necessário um repensar, um compartilhar, negociando culturas, mundos imaginais e bacias semânticas, ${ }^{16}$ ao resgatar as idéias de Madaleine Leininger, de que é preciso envolver, nesse não amamentar e ter que amamentar a negociação de cultura do cuidado popular e do cuidado profissional, sem imposições. É preciso lembrar que é preciso relativizar, é preciso mergulhar nessas diferentes culturas, nesses diversos mundos e distintas bacias, possibilitando re-significações, sem imposições, autoritarismos ou paternalismos. ${ }^{16}$

É preciso, sim, trocar, negociar e repensar a cultura do não amamentar e ter que amamentar, lembrando seus riscos, vindos de uma ditadura expressa por outras culturas que se entrelaçam, não esquecendo do querer, poder amamentar, ${ }^{17} \mathrm{e}$ questionando quando surge a pergunta se o amamentar é sina ou prazer. ${ }^{18}$ Enfim, é preciso sair da lógica da cultura do ter que, do dever ser, para a lógica e a cultura do ser preciso, afinal esta brota das necessidades e desejos de cada ser! ${ }^{17}$

O MCE junto à mulheres-avós e seus familiares em processo de amamentação validou a importância de se colocar em foco o cotidiano, se efetivamente pensarmos em cuidado sintonizado na real existência dos seres humanos. Cotidiano este, entendido como a maneira de viver dos seres humanos que se mostra no dia-dia e se expressa por interações, crenças, valores, imagens, significados e símbolos, estando relacionada à cultura em que estão inseridos, que vai construindo seu processo de viver, num movimento de ser saudável e adoecer, delineando seu ciclo vital, sendo expresso por interações experimentadas diariamente, possibilitando ou não, ao ser humano crescer e se desenvolver ao longo de sua vida.

\section{REFERÊNCIAS}

1 Simons DA. Alimentos complementares ao desmame: quais, quando e como introduzi-los? In: Rego JD. Aleitamento materno. Rio de Janeiro (RJ): Atheneu; 2000.

2 Martins Filho J. Evolução do aleitamento materno no Brasil. In: Rego JD. Aleitamento materno. Rio de Janeiro (RJ): Atheneu; 2000.

3 Ministério da Saúde (BR). Programa Nacional de Incentivo ao Aleitamento Materno. Brasília (DF): MS; 1991. 
4 Araújo MD. Situação e perspectivas do aleitamento materno no Brasil. In: Carvalho MR, Tamaz NR Amamentação: bases científicas para a prática profissional. Rio de Janeiro (RJ): Guanabara Koogan; 2002.

5 Teixeira MA. Meu neto precisa mamar! E agora? Construindo um cotidiano de cuidado junto a mulheres-avós e sua família em processo de amamentação: um modelo de cuidar em enfermagem fundamentado no interacionismo simbólico [dissertação]. Florianópolis (SC): UFSC/PEN; 2005.

6 Nitschke RG. Nascer em família: uma proposta de enfermagem para a interação familial saudável [dissertação]. Florianópolis (SC): UFSC/PEN; 1991.

7 Monticelli M. O nascimento como um rito de passagem: abordagem para o cuidado a mulheres e recém-nascidos. São Paulo (SP): Robe Editorial; 1997.

8 Althoff CR. Convivendo em família: contribuição para a construção de uma teoria substantiva sobre o ambiente familiar. Florianopólis (SC): UFSC/PEN; 2001. [Série Teses em Enfermagem, n.31].

9 Blumer H. Symbolic interactionism: perspective and method. Berkeley (CA/USA): University of California Press; 1969.

10 Nitschke RG. Uma viagem pelo mundo imaginal de ser família saudável no cotidiano em tempos pós-modernos: a descoberta dos laços de afeto como caminho numa viagem ao quotidiano em tempos pós-modernos. Pelotas (RS)/Florianópolis (SC): Ed. Universitária UFPel/Ed. da UFSC; 1999.

11 Cardozo JS; Rodrigues J. O Quotidiano do processo de cuidar da criança desnutrida hospitalizada: um fortalecimento de pontes entre equipe multiprofissional e família sob um enfoque sócio-cultural [TCC]. Florianópolis (SC): UFSC/Curso de Graduação em Enfermagem; 2000.

12 Tholl AD. Os bastidores do cotidiano: as interações entre a equipe de enfermagem e o acompanhante profissional da saúde [dissertação]. Florianópolis (SC): UFSC/PEN; 2002.

13 Silva LC. Compreendendo os significados da morte e do morrer para a equipe de saúde no processo de hospitalização infantil: construindo possibilidades de cuidado ao cuidador [dissertação]. Florianópolis (SC): UFSC/PEN; 2002.

14 Trentini M, Pain L. Pesquisa em enfermagem: uma modalidade convergente-assitencial. Florianópolis (SC): Ed. da UFSC; 2004.

15 Ministério da Saúde (BR), Conselho Nacional de Saúde, Comissão Nacional de Ética em Pesquisa. Resolução No 196 de 10 de outubro de 1996: diretrizes e normas regulamentadoras de pesquisa envolvendo seres humanos. Bioética.1996; 4 (supl. 2): 15-25.

16 Teixeira MA, Nitschke RG, De Gasperi P, Siedler MJ. Significados de avós sobre a prática do aleitamento materno no cotidiano familiar: a cultura do quererpoder amamentar. Texto Contexto Enferm. 2006 Jan-Mar; 15 (1): 98-106.

17 Araújo LDS. Querer/poder amamentar: uma conquista de representação? Londrina (PR): Ed. UEL; 1997.

18 Pereira CS. Amamentação: desejo ou sina?, ensinando e aprendendo com as mulheres [dissertação]. Florianópolis (SC): UFSC/PEN; 1999. 
